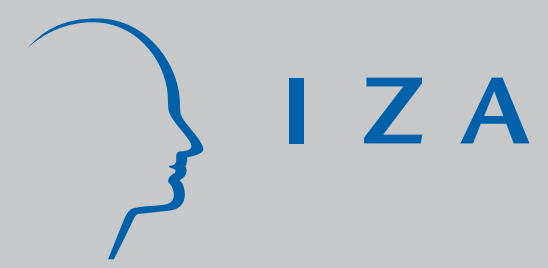

IZA DP No. 5521

The Unequal Incidence of Non-Standard Employment across Occupational Groups: An Empirical Analysis of Post-Industrial Labour Markets in Germany and Europe

Paul Marx

February 2011 


\title{
The Unequal Incidence of Non-Standard Employment across Occupational Groups: An Empirical Analysis of Post-Industrial Labour Markets in Germany and Europe
}

\author{
Paul Marx \\ University of Cologne \\ and IZA
}

\author{
Discussion Paper No. 5521 \\ February 2011 \\ IZA \\ P.O. Box 7240 \\ 53072 Bonn \\ Germany \\ Phone: +49-228-3894-0 \\ Fax: +49-228-3894-180 \\ E-mail: iza@iza.org
}

Any opinions expressed here are those of the author(s) and not those of IZA. Research published in this series may include views on policy, but the institute itself takes no institutional policy positions.

The Institute for the Study of Labor (IZA) in Bonn is a local and virtual international research center and a place of communication between science, politics and business. IZA is an independent nonprofit organization supported by Deutsche Post Foundation. The center is associated with the University of Bonn and offers a stimulating research environment through its international network, workshops and conferences, data service, project support, research visits and doctoral program. IZA engages in (i) original and internationally competitive research in all fields of labor economics, (ii) development of policy concepts, and (iii) dissemination of research results and concepts to the interested public.

IZA Discussion Papers often represent preliminary work and are circulated to encourage discussion. Citation of such a paper should account for its provisional character. A revised version may be available directly from the author. 
IZA Discussion Paper No. 5521

February 2011

\section{ABSTRACT \\ The Unequal Incidence of Non-Standard Employment across Occupational Groups: An Empirical Analysis of Post-Industrial Labour Markets in Germany and Europe}

The paper addresses an often neglected question in labour market research: to which extent do outcomes aggregated on the national level disguise occupational diversity in employment conditions? In particular, how and why do occupational groups differ with regard to the incidence of non-standard employment? To explore these questions, the paper derives a detailed occupational scheme from the literature, capturing the variety of labour market outcomes within countries. In a second step, the scheme is theoretically linked to the topic of non-standard work. It is argued that different degrees of skill specificity across occupational groups produce diverging incentives for flexible and long-term employment, respectively. This leads to the expectation of (some) service-sector occupations showing stronger tendencies towards non-standard employment than those in the industrial sector. Based on European and German micro data, the categorisation is used to decompose various labour market indicators. The results clearly demonstrate the unequal incidence of non-standard employment along the lines of the suggested categorisation. Moreover, the longitudinal perspective suggests that traditionally functioning occupational groups will be crowded out by more destandardised ones.

JEL Classification: J21, J24, J31

Keywords: temporary employment, low-pay, labour market dualisation, occupational groups, post-industrial labour markets, Germany

Corresponding author:

Paul Marx

IZA

P.O. BOX 7240

53072 Bonn

Germany

E-mail: marx@iza.org 


\section{Introduction}

In the academic debate, European labour markets are seen to be in a process of transformation (Barbieri, 2009; Boeri and Garibaldi, 2009; Bosch et al., 2009). Arguably, the development over the past decades has been characterised by two important trends: deindustrialisation and the growth of non-standard work. Up to the 1980, many European countries were characterised by high shares of industrial employment and relatively standardised working conditions. Hallmarks of this traditional employment model were stable career patterns, typically within one firm, and sufficient wages with limited dispersion across the workforce. This did, of course, never reflect the reality for all workers in the labour market. But with a dominant manufacturing sector (often serving as model for other industries), European labour markets produced rather egalitarian outcomes.

With the growth of the service economy, most of these labour markets seemingly lost the ability to ensure standardisation of employment relationships and displayed trends towards “non-standard” or, as Esping-Andersen (1999: 107) puts it, "lousy jobs”. In the scientific literature it is often argued that both developments (deindustrialisation and destandardisation) are interrelated. Accordingly, the rise of service jobs, in particular those with low productivity, has increased pressure for wage inequality (Esping-Andersen, 1993; Iversen and Wren, 1998). Countries which due to institutional rigidities are not able to respond to this pressure with greater wage dispersion may respond with an increasing differentiation by employment contract, i.e. "dualisation” between permanent and temporary work (DiPrete, et al., 2006; Palier and Thelen, 2010; King and Rueda, 2008).

Hence, it is usually assumed that deindustrialisation and service sector growth are important factors driving changes towards more unequal labour market outcomes, be it in terms of wages or employment contract. This implies that beyond labour market indicators aggregated at the national level, we can expect to observe marked differences across sectors and occupations within countries (Eichhorst and Marx, 2010; Häusermann and Schwander, 2009). However, this is not reflected in the typical research design of comparative labour market studies focusing on national cases or regimes (e.g. Auer and Cazes, 2003; Baranowska and Gebel, 2010; Boeri and Garibaldi, 2009; Bosch et al., 2009; Kahn, 2007; Muffels and Luijkx, 2008; Schmid, 2007). Within-country variation is usually only accounted for, if at all, by controlling for industries.

The aim of this paper is to explore the role of occupational heterogeneity for changes in European labour markets, an often neglected topic in comparative labour market research. 
The underlying hypothesis is that the ongoing trend of a growth in non-standard work proceeds asymmetrically, with (some) service-sector occupations being more heavily affected than those in the industrial sector. In this paper the term non-standard work is used in a broader sense. It denotes all deviations from what is usually understood to be a standard work contract, i.e. permanent employment with decent wages and social security coverage. Thus, it covers temporary as well as low-pay work, but not part-time (which excludes many women working voluntarily part-time but sharing all other elements of standard employment).

The observation of varying degrees of non-standard work across occupations is, of course, not new (e.g. Bosch and Lehndorff, 2005), but it raises empirical and theoretical questions which have not been addressed systematically in the current literature. First of all, the service sector is an extremely heterogeneous category comprising occupations with very different skill requirements and work environments. Since the service sector is obviously too broad a category to study differences in labour market patterns, the primary aim of this article is to identify relevant occupational cleavages. Thus, its first contribution is a differentiated categorisation of diverging occupational "employment logics" with regard to non-standard work.

The second, far more ambitious question is how to explain the unequal incidence of nonstandard work across occupational groups. Which characteristics of occupations produce theses differences? Clearly, the chances to obtain a decent (i.e. standard) employment contract are determined by the worker's productivity (Kahn, 2007). However, this holds true for the entire labour market and cannot account for occupational or sectoral differences. Drawing on insight in the literature on post-industrial class schemes, I argue that employees cannot only be distinguished by their productivity, but also by the "work logic" they follow (Kitschelt and Rehm, 2006; Oesch, 2006). I argue that the major difference between workers is whether they are integrated into large organisations and complex divisions of labour or whether they predominantly perform tasks independently. Related to this, workers can either have skills which are bound to a specific context or general ones which are applicable in many jobs and occupations. In contrast to general skills, specific skills are seen to lead to a higher stability orientation on the side of employers (Acemoglu and Pischke, 1999). The argument here is that individualised occupations with rather general skills, which are characteristic for some service industries, can be expected to have a stronger tendency towards flexibility and therefore nonstandard work.

The article adds to the literature in two ways: first, by specifying which occupational clusters underlie the often assumed link between deindustrialisation and labour market change towards 
non-standard employment, and second, by providing an explanation for these differences based on the organisation of the work process and skill specificity.

The article is structured as follows. The first section derives a theoretically grounded occupational categorisation from the literature and discusses its relevance for the topic of nonstandard employment. The empirical part applies the categorisation on two levels: first, its relevance is demonstrated in a cross-country framework based on data from the EU Labour Force Survey (EU LFS). Second, based on more detailed national panel data from Germany, a finer-grained analysis of employment patterns is conducted. Besides contract type, this allows including important aspects such as wages, job stability and social security coverage. Germany is appropriate as an "illustrative example", since it is seen as a major case of labour market flexibilisation by means of non-standard employment (Palier and Thelen, 2010). A final section concludes.

\section{Explaining the unequal incidence of non-standard employment: How to categorise?}

Assuming an unequal incidence of non-standard employment across segments of national labour markets leads to the question how to define the dividing lines. Generally, a sectoral perspective (e.g. NACE) is not suitable, since it does not make a hierarchical differentiation, e.g. by required skills. Hence, the industry alone provides incomplete information on the status of a worker. At higher levels of aggregation, occupational categorizations (e.g. ISCO) are too broad and many groups comprise quite heterogeneous occupations. This may disguise substantial differences in labour market outcomes. If a finer-grained level is chosen, such as ISCO three or four-digit codes, the analysis becomes overly complex with case numbers by category being rather small in most data sets.

A good starting point for a theoretically substantiated classification is provided by the discussion on social classes in the service economy (e.g. Erikson and Goldthorpe, 1992; Esping-Andersen, 1993; Goldthorpe, 1982; Häusermann and Schwander, 2009; Kitschelt and Rehm, 2006; Oesch, 2006). This literature basically argues that the status in the labour market demarcates social classes which share political interests or a common identity. While in a traditional version, this primarily means an antagonism between manual workers, the middle class and capital owners, recent contributions propose more differentiated schemes accounting for the occupational heterogeneity of post-industrial societies (e.g. Kriesi, 1998; Müller, 1999). 
A widely cited framework by Oesch (2006: chap. 5) proposes to categorise occupations according to two dimensions. The first (vertical) one is the skill level, which determines how "valuable" a worker is from the employer's perspective. The higher the skill level, the more favourable the employment relationship is expected to be for the worker. Secondly, the workforce in post-industrial economies is structured horizontally along the "work logic". Underlying dimensions of this distinction are the setting of the work process (including the tasks primarily performed), the relations of authority or command structure, the primary orientation of the worker (towards customers, the organisation or the professional community) and the types of required skills (ibid.: 64). Based on these dimensions, three different work logics are distinguished. First, the "technical work logic" is related to the manufacturing of goods, be it the production itself or a superordinate task such as development or supervision. The "organisational work logic" comprises administrative and clerical tasks on different hierarchical levels in bureaucratic organisations. Finally, the "interpersonal work logic" applies to occupations that involve personal interaction with customers, in particular the provision of personal and social services. The distinct characteristics of the work logics are developed in greater detail below. Combining the two dimensions (work logic and skill level) leads to a $3 \mathrm{x} 3$ matrix and nine occupational groups ${ }^{1}$ (table 1).

Table 1: Occupational groups and typical occupations (in italics)

\begin{tabular}{|c|c|c|c|}
\hline Skill & Technical work logic & Organisational work logic & Interpersonal work logic \\
\hline High & $\begin{array}{l}\text { Technical experts } \\
\text { engineer, technician }\end{array}$ & $\begin{array}{l}\text { Managers/administrators } \\
\text { accountant, manager }\end{array}$ & $\begin{array}{l}\text { Sociocultural profession. } \\
\text { artist, lawyer, teacher }\end{array}$ \\
\hline Medium & $\begin{array}{l}\text { Skilled crafts } \\
\text { electrician, mechanic }\end{array}$ & $\begin{array}{l}\text { Skilled office } \\
\text { office clerk }\end{array}$ & $\begin{array}{l}\text { Skilled services } \\
\text { medical assistant }\end{array}$ \\
\hline Low & $\begin{array}{l}\text { Routine operatives } \\
\text { assembler, labourer }\end{array}$ & $\begin{array}{l}\text { Routine office } \\
\text { telephone operator }\end{array}$ & $\begin{array}{l}\text { Routine services } \\
\text { cleaner, salesperson }\end{array}$ \\
\hline
\end{tabular}

Source: Modified scheme based on Oesch (2006: 68 and 222). Agricultural occupations and armed forces are omitted.

It has to be stressed that the class literature is mainly interested in variables such as social identity and political preferences, which are rather remote from this article’s focus on nonstandard employment. However, what underlies the shared interests of occupational groups are - at least to a certain extent - similar risk patterns and distributional outcomes in the labour market (Kitschelt and Rehm, 2006; Häusermann and Schwander, 2009). So while the

\footnotetext{
${ }^{1}$ Based on Oesch's (2006: 68 and 222) collapsed scheme (without adjusting for education). Two modifications were made: first, self-employed are not treated as a separate group, but integrated in the category matching their activity. Self-employment can serve as a functional equivalent to other non-standard jobs and therefore are a relevant aspect of occupational employment patterns. Second, agricultural occupations and armed forces are omitted.
} 
class literature uses occupational groups as an explanatory variable because of related employment patterns, I am interested in the employment patterns themselves. The focus on employment-related risks makes class schemes a plausible starting point for this study.

How exactly is the occupational scheme presented above related to the incidence of nonstandard work? As for the vertical differentiation by skill level, the answer is straightforward. Such employment can be usually seen as an inferior status in the labour market. Thus, one would expect workers with low skills (and a weak position in negotiations) to be overrepresented in this segment (Kahn, 2007). The expectations for the horizontal structure (work logic) are less intuitive. I argue that different "stability orientations" of employers prevail in the three work logics creating diverging incentives to offer non-standard employment contracts. These, in turn, are primarily explained by the type of skills required in an occupation.

The distinction between specific and general skills has a long-standing tradition in the social sciences (e.g. Becker, 1964; Estevez-Abe et al., 2001; Acemoglu and Pischke, 1999). Specific skills are bound to a particular context (e.g. the firm) and are not transferable. For workers such skills create the threat of sunk costs in case of job loss, but they are also consequential for employers' optimal human resource practices. The dual labour market theory of the 1970s and 1980s identified skill specificity as a crucial variable explaining different degrees of exposure to the market mechanism across workers. While specialised workforces are integrated into internal labour markets offering stable careers, workers without specific skills are exposed to external markets and are used to absorb fluctuations in demand (Doeringer and Piore, 1971: chap. 2; Piore, 1980). In terms of its economic function, this older dualism between external and internal markets largely corresponds to the more recent differentiation by employment contract (Rosenberg, 1991), in particular when strict dismissal protection for regular worker is in place. The major difference is that many countries nowadays regulate secondary employment with a distinct legal framework (e.g. fixed-term contracts). Based on dual labour market theory, one could thus argue that the distribution of standard and nonstandard contracts is influenced by the types of skills. In a stylised fashion, the former can be seen as a means of stabilising specific human capital, the latter as an option to flexibly employ workers without specific skills.

The reason for the differentiation by skill type is that, analogously to the worker's hold-up problem, employers face difficulties to replace a specifically trained worker, especially when they contributed to human capital investment (Busemeyer, 2009). Thus, specific skills create a mutual interest in long-term employment relationships (Emmenegger, 2009), which should 
foster employers’ propensity to offer stability-oriented contracts (with permanent duration, seniority pay, etc.). Workers with low or general skills, however, make a more flexible contractual arrangement attractive to the employer.

Polavieja (2005; 2006) challenges dual labour market theory's usefulness for explaining the incidence of temporary employment by showing empirically that such work is not limited to low-skilled occupations, but affects high-skilled professionals as well. However, in his argument he refers to the hierarchical differentiation by skill level only, without accounting for varying degrees of skill specificity across work logics (the horizontal differentiation suggested in this paper). If it is acknowledged that these variations exist (and that high-skill occupations can have rather general human capital), his findings are not at odds with the basic argument of dual labour market theory.

As I argue below, there are in fact reasons to expect different degrees of skill specificity across work logics, variation across countries and production models notwithstanding (Estevez-Abe et al., 2001). With some simplification, it can be argued that the interpersonal work logic stands out in this respect. Most importantly, it represents an extensively individualized segment where "orders will come more from customers than from bosses" (Esping-Andersen, 1999: 106). Hence, the work process mainly consists of personal interactions with clients. It usually demands a high degree of social competencies, in particular communicative ones (plus varying degrees of expertise, depending on the skill level). Such competencies are very general and therefore portable across jobs and occupations. Moreover, most tasks within the interpersonal work logic are performed individually, i.e. independent of location, equipment and co-workers. Service providers basically rely upon their personal skills, which usually do not have to be integrated in a complex division of labour (Oesch, 2006: 64), but in many cases can be offered by single entrepreneurs. Hence, this logic predominantly involves skills which are not bound to a specific organisation or even a particular occupation.

This does also apply to academics. Knowledge-intensive and creative service industries are typically characterised by a rather low stability orientation on the part of employers in order to be adaptable to radically changing demands. Rather than permanence, the employment relationship offers work experience, adding to general skills and external "employability" (Collins, 2006). Marsden (2010) points to the consequences of such employment patterns in high-skilled knowledge-intensive service industries for individual work biographies. Accordingly, entrants in this segment have to participate in "extended entry tournaments" dividing workers into winners and losers with the latter being persistently kept from stable 
employment. Such "unstructured" career paths demand more individual efforts and skill investments. This perspective supports the expectation that the interpersonal work logic goes along with more flexible employment relationships, also on high skill levels. It is noteworthy, however, that unstructured career tracks do not lead to lower remuneration, as more risky careers are usually compensated with wage premiums - at least for winners of entry tournaments (ibid.: 4).

The expectations are quite different for the technical work logic. Jobs that are concerned with the development and production of goods tend to benefit to a higher degree from tenure and tacit knowledge on the specific product, particularly in high value-added manufacturing. This is the case, for instance, because special machines are involved or because of incremental innovation processes based on long-standing exchange with customers. Moreover, economies of scale and the complexity of the production process usually bind the technical work logic to larger organisational units. Performing tasks in attuned teams may entail a further aspect of specificity, especially as the interaction is typically associated with informal on-the job learning (Doeringer and Piore, 1971: 22). Because the technical work logics is associated with larger production units and rather specific skills, it is biased towards "structured" career paths in internal labour markets (Marsden, 2010). Only expected tenure and within-firm job progression make joint investments in human capital possible.

The expectations for the organisational work logic with regard to skill specificity are less clear. The main competencies are coordinative and clerical, and therefore probably more portable (and replaceable) than in the technical logic. However, by definition, such occupations are located in larger bureaucratic organisations (Oesch, 2006: 64), which have specific work processes and divisions of labour. Very often these organisations have idiosyncratic tasks, regulations or technologies, which bind work experience to a specific context. One example would be the use of software specifically designed for the purposes of an organisation. Hence, similar to the technical work logic, one can expect structured careers and internal labour markets to play an important role in the organisational logic. Public administration is a case in point.

The upshot is that due to different degrees of skill specificity, we can expect the "stability orientation" in the organisational and technical work logic to be higher than in the interpersonal work logic. As the interpersonal work logic by tendency is associated with individualised and project-based work as well as more general skills, flexible forms of employment are relatively attractive in this realm. Thus, two hypotheses can be extracted from the discussion: 
Hypothesis 1: On the vertical dimension, the incidence of non-standard work varies across skill levels, with routine jobs being less stable and more exposed to temporary contracts as well as low wages.

Hypothesis 2: On the horizontal dimensions, the incidence of non-standard work varies across work logics. For high- and medium-skilled occupations, the interpersonal work logic is expected to exhibit less stability and more temporary contracts, but not lower wages.

Two qualifications are in order. First, the above framework is clearly a stylised one, disguising considerable heterogeneity of occupations within work logics. Thus, occupational groups are far from being deterministic predictors of labour market outcomes. The scheme represents a parsimonious and theoretically-grounded heuristic device; whether it is meaningful is an empirical question. Second, the impact of membership in an occupational group may be subject to a "societal effect”. Employment patterns could differ across countries due to institutional factors and production models (Bosch and Lehndorf, 2005; EspingAndersen, 1999: chap. 7). While this question is beyond the scope of the present article, it poses a challenge for future research on the subject.

Bearing these qualifications in mind, the subsequent sections will attempt at establishing the empirical relevance of occupational groups for comparative labour market research in general and the incidence of non-standard employment in particular.

\section{Occupational employment patterns in a comparative perspective}

Initially, the occupational scheme presented in table 1 is applied to a selected number of EU15 countries. The sample is chosen in such a manner that it covers the largest member states and all welfare regimes. Unfortunately, the data source (EU LFS) does not provide information on relevant aspects (e.g. pay and mobility). Thus, the comparison is restricted to the incidence of non-standard work contracts, defined here as either fixed-term or agency work or part-time below 15 hours per week. Such "marginal” part-time is included, since it can be expected to generate only low earnings and because it is not covered by unemployment insurance in some countries.

Figure 1 shows a considerable occupational heterogeneity in all countries. As predicted by hypothesis 1 , routine occupations exhibit the highest shares within each work logic in most cases (an exception is Spain, where skilled crafts and office have equally high shares). 
Moreover, the descriptive data partly lends support to hypothesis 2 . In each country the share of non-standard employment among socio-cultural professionals exceeds levels in the two other high-skilled groups (technical experts and managers). In five out of six countries they are even higher than the shares among the medium-skilled occupations of the other logics. While this confirms the expectations for the interpersonal work logic, skilled services do not exhibit higher shares of non-standard contracts than their counterparts in the other logics (this is only true for Sweden). Hence, the interpersonal work logic appears more polarised in terms of non-standard employment with higher shares in both high- and low-skilled occupations.

Figure 1: Share of atypical workers (temporary contracts and marginal part-time ${ }^{a}$ ) by occupational group $^{b}$ and country, 2008

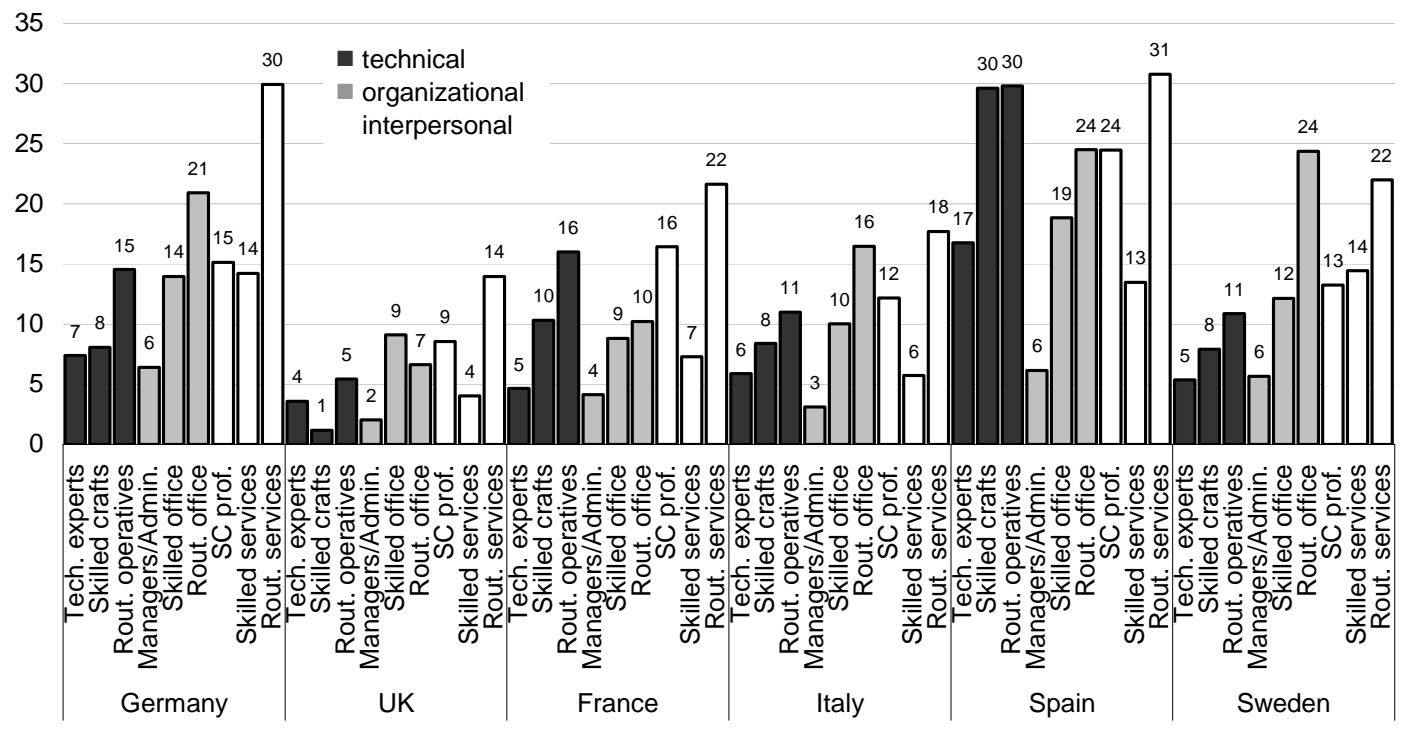

Source: EU LFS 2008.

Note: Results for France should be interpreted with caution due to high number of missing values (ca. $5 \%$ of the sample). ${ }^{a}$ defined as part-time with $<15 \mathrm{~h}$ per week; ${ }^{b}$ based on the modified scheme of Oesch (2006) presented in table 1. Some further modifications were necessary as only three-digit ISCO codes were available (STATA codes can be obtained from the author upon request).

The descriptive overview provides some preliminary evidence that the suggested categorisation identifies meaningful occupational patterns in terms of non-standard employment. The results are in line with the theoretical expectation of a stronger reliance on non-standard work in the interpersonal work logic, although this could only be confirmed for academic and routine occupations. Moreover, the data points to significant country differences concerning the overall level and distribution of non-standard work. Notwithstanding these differences, however, Figure 1 also shows that occupational gaps are present in all countries and that they exhibit a largely comparable structure. This suggests the 
insights of the following case study on Germany to be potentially relevant for other countries as well.

\section{Occupational employment patterns in Germany: Employment contracts and wages}

Turning now to the German case allows using a more detailed data source (the German SocioEconomic Panel, GSOEP) and additional indicators. Table 2 presents some basic characteristics of the occupational groups in Germany. The largest group is the one of managers and administrators, followed by socio-cultural professionals and skilled crafts. The development over time illustrates the process of deindustrialisation: since the mid-1990s the most dynamically growing occupations can be found in the service sector (particularly sociocultural professionals), while the only group with significant losses is the one of skilled crafts. Concerning the skill composition, the technical and organisational work logics have their smallest employment shares in routine occupations. The interpersonal work logic has a polarised employment structure with only a small proportion of medium-skilled jobs. A similar tendency can be observed in the other logics as well, where the medium-skilled groups have been shrinking since 1995.

Table 2: Types of employment in occupational groups, 1995 and 2008

\begin{tabular}{|c|c|c|c|c|}
\hline & \multicolumn{4}{|c|}{ \% (change since 1995) } \\
\hline & $\begin{array}{c}\text { Of total } \\
\text { employment }^{a}\end{array}$ & $\begin{array}{c}\text { Permanent } \\
\text { contract }^{b}\end{array}$ & $\begin{array}{c}\text { Self- } \\
\text { employment }\end{array}$ & $\begin{array}{c}\text { Non-standard } \\
\text { contract }^{c}\end{array}$ \\
\hline Technical experts & $10(0)$ & $77(-2)$ & $12(+1)$ & $8(+1)$ \\
\hline Skilled crafts & $15(-5)$ & $74(-4)$ & $10(+1)$ & $10(+4)$ \\
\hline Routine operatives & $8(0)$ & $74(-11)$ & $0(-1)$ & $24(+13)$ \\
\hline Managers/admin. & $20(+1)$ & $75(0)$ & $15(-2)$ & $8(+4)$ \\
\hline Skilled office & $10(-2)$ & $79(-3)$ & $1(0)$ & $14(+5)$ \\
\hline Routine office & $3(+1)$ & $69(-18)$ & $1(0)$ & $27(+14)$ \\
\hline SC professionals & $15(+4)$ & $62(-8)$ & $16(+2)$ & $20(+8)$ \\
\hline Skilled services & $4(+1)$ & $67(-12)$ & $11(+3)$ & $13(+6)$ \\
\hline Routine services & $14(+2)$ & $61(-14)$ & $3(+2)$ & $33(+12)$ \\
\hline Total & $98(+1)$ & $69(-7)$ & $10(+1)$ & $18(+8)$ \\
\hline
\end{tabular}

The distribution of standard and non-standard employment resembles that of figure 1: routine operatives as well as socio-cultural professionals exhibit particularly high shares of the latter. It is worth noting that socio-cultural professionals, in addition to an above-average share of 
non-standard work, have the highest portion of self-employment. This culminates to a rather low incidence of permanent employment in this group.

The development over time shows that the dynamically growing groups also tend to be the ones with the highest shares or growth of non-standard contracts (except for routine operatives). Accordingly, shifts in the occupational composition appear to be a relevant factor underlying change of the German employment model. This is illustrated in figure 2, which plots trends in overall as well as permanent employment for each group against each other. It clearly shows the higher dynamic in those groups that at the same time drift towards a fragmented employment model. Thus, change in the German labour market proceeds anything but uniform across occupations. Rather, occupations increasingly characterised by nonstandard work (interpersonal work logic and routine office) seem to be in a process of crowding-out more stable and homogeneous groups (in particular skilled crafts and office).

Figure 2: Share of permanent contracts and share in total employment (1995=100) by occupational group, 2008

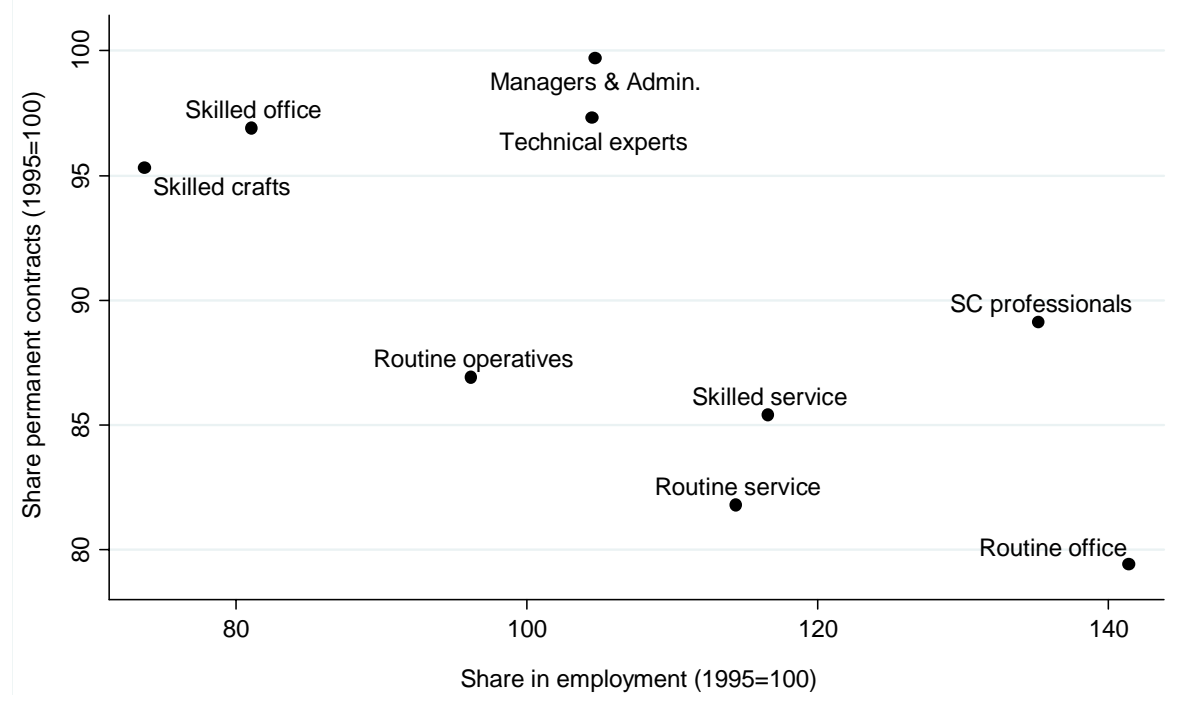

Source: SOEP 1995 and 2008

Besides the employment contract, relative wage levels are an important aspect for assessing the quality of employment. Table 3 presents three indicators. The median gross hourly wage, unsurprisingly, reflects skill levels in each group. Beyond that, it is difficult to interpret, since the composition of the groups is not known. It indicates routine services to be characterised by rather low wages, also in comparison to other low-skilled occupations. Large differences can be observed with regard to the standard deviation. Wage dispersion is relatively low in the technical as well as in the organisational work logic. This reflects the effect of public sector 
pay schemes and the rather high collective bargaining coverage in relevant sectors. In Germany collective bargaining coverage is high in manufacturing as well as in public and non-commercial services, but relatively low in market-related services (Eichhorst and Marx, 2010). Accordingly, wage dispersion among socio-cultural professionals is much higher than in any other group. This can be interpreted as a first evidence for the effect "entry tournaments" on the relative pay of high-skilled service sector workers. Compressed wages in skilled and routine services reflect concentration on the lower end of the wage scale, as is revealed by their large low-pay share. The same holds for routine operatives and office. For these groups the absence of a statutory minimum wage in Germany seems to matter. Over time the lower tiers in each logic drifted in the direction of more wage flexibility. However, the development since 1995 suggests that the overall increase of low-pay work is again predominantly driven by the expanding occupational groups of the service sector.

Table 3: Gross hourly wages in salaried employment by occupational group, 2008

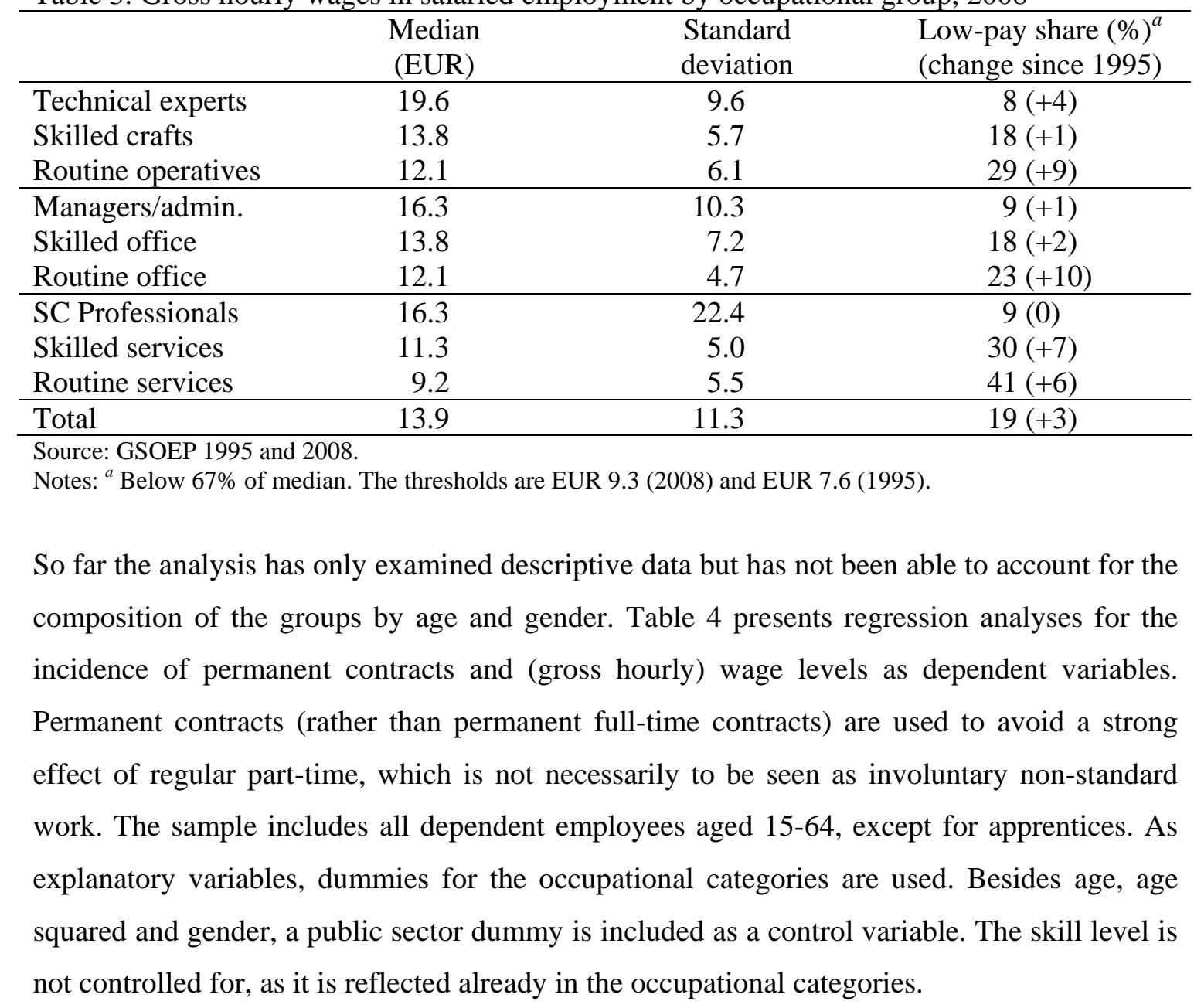


The controls have significant effects in the expected direction. Age increases the odds of having standard contracts and wages. The same is true for the public sector dummy, while being female is associated with a wage gap and lower chances of holding a standard contract. Concerning the occupational groups, the regression analyses confirm the descriptive observations. In comparison to the reference category (skilled crafts) routine operatives, socio-cultural professionals and routine services show significantly lower likelihoods of holding a permanent contract (routine office is only weakly significant). The only group with a significantly higher likelihood is the one of managers and administrators. This supports the initially formulated hypotheses: low-skilled workers, as well as the interpersonal work logic (except for the medium skill level), have more flexible contractual arrangements than traditional manufacturing occupations.

Table 4: Regression analysis: odds of having a permanent contract, logarithm of gross hourly wage and tenure

\begin{tabular}{|c|c|c|c|}
\hline & \multicolumn{3}{|c|}{ Dependent variables } \\
\hline & $\begin{array}{c}\text { Permanent } \\
\text { contract }^{a}\end{array}$ & $\begin{array}{c}\text { Log gross } \\
\text { hourly wage }\end{array}$ & Tenure $^{b}$ \\
\hline Constant & - & 1.275 & $-4.589^{* * *}$ \\
\hline Age & $1.28^{* * *}$ & $0.056^{* * *}$ & $0.261^{* * *}$ \\
\hline Age $^{2}$ & $1.00^{* * *}$ & $-0.006^{* * *}$ & $-0.003^{* *}$ \\
\hline Female & $0.50^{* * *}$ & $-0.259^{* * *}$ & $-1.681^{* * *}$ \\
\hline Public sector & $1.59^{* * *}$ & $0.045^{* *}$ & $4.206^{* * *}$ \\
\hline \multicolumn{4}{|l|}{ Occupation (ref: Skilled crafts) } \\
\hline Technical experts & 1.35 & $0.394^{* * *}$ & -0.235 \\
\hline Routine operatives & $0.50^{* * *}$ & $-0.082^{* * *}$ & $-1.526^{* * *}$ \\
\hline Managers and administrators & $1.49^{* *}$ & $0.323^{* * *}$ & 0.195 \\
\hline Skilled office & 1.06 & $0.175^{* * *}$ & $1.340^{* *}$ \\
\hline Routine office & $0.61^{*}$ & $0.070^{*}$ & -1.331 \\
\hline Socio-cultural professionals & $0.45^{* * *}$ & $0.330^{* * *}$ & $-2.562^{* * *}$ \\
\hline Skilled services & 0.91 & $-0.153^{* * *}$ & -0.837 \\
\hline Routine services & $0.39^{* * *}$ & $-0.215^{* * *}$ & $-3.481^{* * *}$ \\
\hline $\mathrm{N}$ & 8,642 & 7,625 & 8,637 \\
\hline (Pseudo) R² & 0.12 & 0.30 & 0.35 \\
\hline
\end{tabular}

Source: GSOEP $2008\left(* * *=\right.$ significant on $1 \%$-level $\left.{ }^{* *}=5 \%{ }^{*}=10 \%\right)$.

Notes: The sample includes all dependent employees aged 15-64 except for apprentices; ${ }^{a}$ binary logistic regression (odds ratios); ${ }^{b}$ OLS regression.

As for the wage regression, all categories deviate significantly from skilled crafts (routine office only at the ten percent level). After the gender wage gap is controlled for, skilled and routine office occupations pay even higher wages on average than skilled crafts. Skilled and routine services, as well as routine operatives, exhibit significant wage gaps. As expected, the interpersonal work logic is thus associated with on average lower levels of remuneration. What is important, however, is the significant wage premium for socio-cultural professionals, 
which is approximately as large as the ones in other academic occupations. Accordingly, this group is more likely to work under flexible contracts, but on average the wage level is similar to comparable workers in other logics. This confirms the expectations formulated in hypothesis 2 .

\section{Employment stability and social protection}

The topics of employment stability and atypical employment are clearly related, since shortterm contracts are expected to produce more fragmented work biographies. Hence, the different occupational employment patterns observed in the previous sections could go along with diverging unemployment risks. As a first indicator, table 5 presents the average number of months in unemployment per occupational group over a three-year period. Accordingly, workers in routine and skilled services, as well as routine operatives, are, on average, particularly exposed to unemployment. As this indicator is heavily influenced by long-term unemployed entering an occupation (which is more frequently happening in low-skilled occupations), it is also interesting to investigate the stability of employment relationships, which is expressed by average tenure (table 5). It was hypothesised that, besides routine occupations, the interpersonal work logic is particularly unstable. Hence, we would expect lower tenure in this segment, also for high-skilled individuals. At first glance, the descriptive indicator does not reveal such differences. With the exception of routine services, the average of all groups lies in a relatively small range between nine and twelve years. Socio-cultural professionals and skilled services have somewhat lower tenure, but on average the distance is not dramatic.

However, the average tenure in an occupation is heavily influenced by the group's composition, especially with regard to age and public sector employment. To control for these effects and to establish whether differences are significant, table 4 presents results of an OLS regression of tenure on occupational group dummies. Controlling for the age structure, gender and public sector employment shows some significant effects. As was the case for the incidence of permanent contracts, hypothesis two can be confirmed for the high and low-skill segment of the interpersonal work logic only. Hence, socio-cultural professionals as well as routine service workers stay significantly shorter with a firm than the reference category (skilled crafts), but not skilled service workers. For the other groups there are little significant deviations from the reference category. This confirms that, with the exception of routine 
operatives, tenure patterns are relatively homogeneous in the technical and organisational work logic.

Table 5: Unemployment, tenure and unemployment insurance coverage by occupational group

\begin{tabular}{lccc}
\hline & $\begin{array}{c}\text { Average months } \\
\text { unemployed }^{a}\end{array}$ & $\begin{array}{c}\text { Average tenure } \\
\text { (years) }\end{array}$ & $\begin{array}{c}\text { Eligibility to } \\
\text { ALG I (\%) }^{b}\end{array}$ \\
\hline Technical experts & 0.8 & 11.2 & 85 \\
Skilled crafts & 1.6 & 11.2 & 88 \\
Routine operatives & 2.9 & 9.8 & 87 \\
\hline Managers/admin. & 1.0 & 12.0 & 80 \\
Skilled office & 1.4 & 11.5 & 91 \\
Routine office & 1.9 & 9.2 & 79 \\
\hline SC Professionals & 1.1 & 10.4 & 77 \\
Skilled services & 2.4 & 10.3 & 73 \\
Routine services & 3.3 & 7.7 & 79 \\
\hline Total & 1.8 & 10.3 &
\end{tabular}

A further important topic related to employment stability is unemployment insurance coverage. As stressed in the literature on new social risks, traditional welfare states may be illsuited to protect post-industrial employment relationships against the risk of unemployment. The main obstacle is the link between benefit eligibility and previous employment record based on the assumption of a continuous "industrial” work biography (Bonoli 2007; Clasen and Clegg 2006). In recent years work requirements in many Bismarckian welfare states have even been tightened due to increasing cost concerns. As a consequence, more and more unemployed are eligible to only second-tier unemployment assistance (Palier 2010). This also applies to Germany, where unemployed are either eligible to earnings-related unemployment insurance (ALG I) or to a significantly less generous and means-tested basic income scheme (ALG II). Thus, the information to which kind of benefit a worker would be eligible in the case of unemployment is an important indicator for the precariousness of employment in a dynamic perspective.

With the SOEP it is not possible to model eligibility precisely due to incomplete information for periods between surveys. Yet it can be approximated reasonably well. In Germany eligibility to ALG I requires 12 months of employment subject to social insurance contributions in the previous 24 months. Marginal part-time up to a monthly wage of EUR 400 (Minijobs) and self-employed are excluded. In the SOEP there is no information on a job being subject to social insurance contributions, but it provides the number of months per year in salaried employment, which excludes self-employment. Moreover, for each month it can be 
determined whether respondents worked exclusively in a Minijob. Civil servants are not covered by unemployment insurance and therefore excluded from the sample.

Based on this information from two consecutive waves (adding up to the assessment period of 24 months) an indicator for unemployment insurance eligibility can be constructed. More precisely, it expresses the hypothetical eligibility to ALG I for those employed at the time of the 2008 survey, based on the employment record in 2007 and 2008. Eligible are only those who work 12 months or more in salaried employment (excluding Minijobs, but including parental leave and military/civil service). Respondents who do not fulfil this criteria are assumed not to be eligible to ALG I.

The results ${ }^{2}$ are presented in table 5 . Hypothetical eligibility is relatively high in the technical work logic and particularly in the skilled office group. Managers and administrators as well as socio-cultural professionals have somewhat lower rates, which is to be explained from high shares of self-employed (table 2). The same is true, to a lesser extent, for skilled services. The group clearly standing out is the one of routine services where - based on their current employment record - only around two-thirds would be eligible for ALG I. The other indicators suggest this to be the effect of predominantly fragmented or marginal employment. Hence, for the German case the analysis lends support to the claim that Bismarckian welfare states do not fully reflect the risks in post-industrial employment relationships.

\section{Conclusions}

This study aimed at enhancing the discussion on growing non-standard work in European labour markets by offering a differentiated perspective accounting for occupational diversity within countries. As a heuristic tool capturing this variety, an occupational categorisation was derived from the literature. The paper's rather explorative contribution was to illustrate the empirical relevance of this categorisation on the German case, thereby showing that occupational heterogeneity is an important aspect for comparative research on non-standard employment. The two hypotheses guiding the analysis were largely confirmed. Low-wage work, temporary employment and instable work biographies are mainly characteristics of low-skilled jobs. Moreover, the analysis revealed somewhat less intuitive differences across work logics. By and large, the interpersonal work logic appears as a labour market segment in which deviations from the traditional employment model are most pronounced. Compared to

\footnotetext{
${ }^{2}$ There are some inconsistent results, presumably because some respondents misreport Minijobs as regular salaried employment (which makes it impossible to disentangle the two). Although the effect is fairly small, the indicator should only be seen as an approximation.
} 
the standard observed in medium-skilled manufacturing jobs, this was expressed in a significantly higher share of temporary employment, lower tenure and wage penalties. As expected, non-standard contracts and job instability were also relatively high for academics in this logic (socio-cultural professionals), while wages were comparable to other high-skill groups. Deviating from the initial expectations, skilled services do not significantly differ from skilled crafts when it comes to non-standard contracts and tenure, but they do feature a much higher spread of low-wage employment than other medium-skilled groups.

The analysis has also shown that the manufacturing sector (technical work logic), although being relatively stable, is not as homogeneous as it used to be in the industrial era, when strong unions ensured relatively favourable employment conditions also for low-skilled workers. This lower tier of industrial employment has turned into a quite flexible segment with increasing differences to the medium and top tier. Arguably, institutional reforms asymmetrically de-regulating agency work and fixed-term contracts have contributed to this development: since few firm-specific skills are involved in the lower tier, employers face few transaction costs hiring these workers on a temporary basis.

The various empirical pieces presented in the analysis add up to an argument concerning the long-term change of European employment models. As occupational groups feature different employment logics, a shift in the occupational composition of the labour market contributes to change in the overall model. With some simplification, we observe a process in which more traditionally functioning groups are crowded out by more destandardised ones. The upshot of this observation is that if we want to understand change in European labour markets, we need to ask how different occupational employment patterns can be explained. This paper makes a first step in this direction, but there are at least two important tasks for future research on this matter.

The first one lies in exploring in greater detail the role of occupational heterogeneity for aggregated labour market outcomes in a comparative perspective. On the one hand, this would mean assessing how far the occupational composition of national labour markets affects cross-sectional differences. But even more important would be to study the mediating effects of different regulatory frameworks on occupational diversity. As shown by the analysis, highly flexible occupational groups can coexist with more stability-oriented ones in a given regulatory framework. This casts doubt on institutions being the most important explanatory variables for different labour market outcomes across countries. In this perspective, it would be desirable to analyse interaction between institutions and structural conditions in different occupational groups. 
The second possible direction for future research are in-depth case studies of particular occupations establishing causal arguments for diverging labour market patterns. As suggested in this paper (without being investigated empirically), these differences can be explained by the types of skills and related "stability orientations" of employers. However, on the basis of the presented empirical material, this causal argument cannot be evaluated. Qualitative case studies explaining labour market outcomes by occupational differences with regard to skills creation, production models and industrial relations could fill this gap.

\section{References}

Acemoglu, D. and Pischke, J.-S. (1999). Beyond Becker: Training in imperfect labour markets. Economic Journal, 109, 112-142.

Auer, P. and Cazes, S. (2003). The resilience of the long-term employment relationship. In Auer, P. and Cazes, S. (Eds.), Employment Stability in an Age of Flexibility. Evidence from industrialized countries, Geneva: International Labour Office, 22-58.

Baranowska, A. and Gebel, M. (2010). The determinants of youth temporary employment in the enlarged Europe. Do labour market institutions matter?. European Societies, 12, 367390.

Barbieri, P. (2009). Flexible employment and inequality in Europe. European Sociological Review, 25, 621-628.

Becker, G. S. (1975). Human Capital. A theoretical and empirical analysis, with special reference to education. New York: National Bureau of Economic Research.

Boeri, T. and Garibaldi, P. (2009). Beyond Eurosclerosis. Economic Policy, 24, 409-461.

Bonoli, G. (2007). Time matters: Postindustrialization, new social risks, and welfare state adaptation in advanced industrial democracies. Comparative Political Studies, 40, 495520.

Bosch, G. and Lehndorff, S. (2005). Introduction: Service economies - high road or low road? In Bosch, G. and Lehndorff, S. (Eds.), Working in the Service Sector. A tale from different worlds. London; New York: Routledge, 1-32.

Bosch, G., Lehndorff, S. and Rubery, J. (2009). European Employment Models in Flux: Pressures for change and prospects for survival and revitalization. In Bosch, G., Lehndorff, S. and Rubery, J. (Eds.), European Employment Models in Flux. A comparison of institutional change in nine European countries. Basingstoke; New York: Palgrave Macmillan, 1-56.

Busemeyer, M. (2009). Asset specificity, institutional complementarities and the variety of skill regimes in coordinated market economies. Socio-Economic Review, 7, 375-406. 
Clasen, J. and Clegg, D. (2006). Beyond activation: Reforming European unemployment protection systems in post-industrial labour markets. European Societies, 8, 527-553.

Collins, H. (2006). Flexibility and stability of expectations in the contract of employment. Socio-Economic Review, 4, 139-153.

DiPrete, T. A., Goux, D., Maurin, E. and Quesnel-Vallee, A. (2006). Work and pay in flexible and regulated labor markets: A generalized perspective on institutional evolution in inequality trends in Europe and the US. Research in Social Stratification and Mobility, 24, 311-33.

Doeringer, P. B. and Piore, M. J. (1971) Internal Labor Markets and Manpower Analysis. Lexington, Mass: Heath.

Eichhorst, W. and Marx, P. (2010). Whatever works: Dualisation and the service economy in Bismarckian welfare states. IZA Discussion Paper, 5035.

Emmenegger, P. (2009). Specificity versus replaceability: The relationship between skills and preferences for job security regulations. Socio-Economic Review, 7, 407-430.

Erikson, R. and Goldthorpe, J. H. (1992). The Constant Flux. A study of class mobility in industrial societies. Oxford: Clarendon Press.

Esping-Andersen, G. (1993). Post-industrial Class Structures: An Analytical Framework. In Esping-Andersen, G. (Ed.), Changing Classes. Stratification and Mobility in Postindustrial Societies. London: Sage, 7-31.

Esping-Andersen, G. (1999). Social Foundations of Postindustrial Economies. Oxford: Oxford University Press.

Estevez-Abe, M., Iversen, T. and Soskice, D. (2001). Social protection and the formation of skills: A reinterpretation of the welfare state. In Hall, P. A. and Soskice, D. (Eds.), Varieties of Capitalism: The institutional foundations of comparative advantage. Oxford: Oxford University Press, 145-183.

Goldthorpe, J. H. (1982). On the Service-class, its Formation and Future. In Giddens, A. and McKenzie, G., eds., Classes and the Division of Labour. Essays in Honour of Ilya Neustadt. Cambridge: Cambridge University Press, 162-185.

Häusermann, S. and Schwander, H. (2009). Identifying outsiders across countries: Similarities and differences in the patterns of dualisation. RECWOWE Working Paper, 09/2009.

Iversen, T. and Wren, A. (1998). Equality, employment, and budgetary restraint: The trilemma of the service economy. World Politics, 50, 507-546.

Kahn, L. M. (2007). The impact of employment protection mandates on demographic temporary employment patterns: International microeconomic evidence. Economic Journal, 117, 333-356.

King, D. and Rueda, D. (2008). Cheap labor: The new politics of "Bread and Roses" in industrial democracies. Perspectives on Politics, 6, 279-297. 
Kitschelt, H. and Rehm, P. (2006). New social risk and political preferences. In Armingeon, K. and Bonoli, G. (Eds.), The Politics of Post-Industrial Welfare State: Adapting post-war social policies to new social risks. London, New York: Routledge, 52-82.

Kriesi, H. (1998). The transformation of cleavage politics. European Journal of Political Research, 33, 165-185.

Marsden, D. (2010). The growth of extended "entry tournaments" and the decline of institutionalised occupational labour markets in Britain. CEP Discussion Paper, 989.

Muffels, R. and Luijkx, R. (2008). Labour market mobility and employment security of male employees in Europe: "Trade-off" or "flexicurity"? Work Employment and Society, 22, 221-242.

Müller, W. (1999). Class Cleavages in Party Preferences in Germany - Old and New. In Evans, G. (Ed.), The End of Class Politics. Class Voting in Comparative Context. Oxford: Oxford University Press, 137-180.

Oesch, D. (2006). Redrawing the Class Map: Stratification and institutions in Britain, Germany, Sweden and Switzerland. Basingstoke: Palgrave Macmillan.

Palier, B. (2010). The long conservative corporatist road to welfare reforms. In Palier, B. (Ed.), A Long Goodbye to Bismarck? The politics of welfare reform in continental Europe. Amsterdam: Amsterdam University Press, 333-387.

Palier, B. and Thelen, K. (2010). Institutionalizing dualism: Complementarities and change in France and Germany. Politics and Society, 38, 119-148.

Piore, M. J. (1980). Dualism as a response to flux and uncertainty. In Berger, S. and Piore, M. J. (Eds.), Dualism and Discontinuity in Industrial Societies. Cambridge: Cambridge University Press, 23-54.

Polavieja, J. G. (2005). Flexibility or polarization? Temporary employment and job tasks in Spain. Socio-Economic Review, 3, 233-258.

Polavieja, J. G. (2006). The incidence of temporary employment in advanced economies: Why is Spain different? European Sociological Review, 22, 61-78.

Rosenberg, S. (1991). From segmentation to flexibility: A selective survey. Review of Radical Political Economics, 23, 71-79.

Schmid, G. (2007). Comparing the performance of employment systems: Is the Lisbon strategy in the right track? In Jørgensen, H. and Madsen, P. K. (Eds.), Flexicurity and Beyond. Finding a new agenda for the European social model, Copenhagen: DJØF, 3966. 